\title{
Rethinking gender, risk and depression in Australian mental health policy
}

\author{
Dr Simone Fullagar \& Suzy Gattuso
}

School of Community Health, Charles Sturt University, Albury, Australia Mental Health (Auseinet) www.auseinet.com/journal 


\begin{abstract}
In this article we draw upon the work of governmentality and cultural risk theorists (Foucault 1991; Rose 1999; Dean 1999; Lupton 1999) and feminist research into women's experience of depression (Stoppard, 2000) to develop a gendered analysis of recent Australian mental health policies. We explore the power-knowledge relations that shape current policy directions, and hence the thinking that guides health professionals, in relation to women's experience of depression and emotional distress in society today. Policy discourses are a means through which neo-liberal rule is exercised in relation to women's emotional lives as a population and as individuals identified as 'at risk' of mental disorder. Yet, a sociocultural analysis of the gendered experience of depression has been largely ignored within mental health policy that draws upon biomedical and psychological discourses aimed at the prevention, identification and treatment of disorder. We ask where, in this contemporary regime of truth, is there room for women to ask critical questions about their own experiences of selfhood and emotions in contemporary culture, and importantly, to be heard?
\end{abstract}

\title{
Keywords
}

gender, women's depression, governmentality, emotion, mental health policy, feminism

\section{Introduction}

The World Health Organization has predicted that by 2020 depression will constitute one of the greatest health problems world wide, generating significant social and economic costs (Murray and Lopez, 1996). Australia has responded to the international identification of the burden of disease associated with depression by developing the National Action Plan for Depression (CDHAC, 2000a:ix) as part of the National Mental Health Strategy (Thornicroft and Betts, 2002). These policy directions work alongside the National Action Plan for Promotion, Prevention and Early Intervention for Mental Health (CDHAC, 2000b) to focus on achieving a reduction in the prevalence and impact of depression on the Australian community.
Specific targets are set out in relation to the general community, primary care and mental health services while also identifying risk and protective factors for depression.

Within these contemporary mental health policies gender has been recognised in relation to an increased risk of developing a disorder, with women identified as twice as likely as men to experience depression. Women report higher rates of depression across all age groups, the highest being the 18-24 year old group (CDHAC, 2000a). Risk is also identified for women after childbirth, older women in residential care, those in carer roles and those living in rural or isolated areas. In fact depression is presently the leading cause of the non-fatal burden of disease for women in Australia (Australian Institute for Health and Welfare,

\footnotetext{
Contact: Dr Simone Fullagar, School of Community Health, Charles Sturt University, PO Box 789, Albury NSW, Australia 2640 Tel/Fax: 0260270577 Email: sfullagar@csu.edu.au

Citation: Fullagar, S. \& Gattuso, S. (2002) Rethinking gender, risk and depression in Australian mental health policy. Australian e-Journal for the Advancement of Mental Health 1(3) www.auseinet.com/journal/volliss3/fullagar.pdf
} 
2000). Gender is often explained in relation to the cause of depression as a 'cover all bases' combination of bio-psycho-social influences (Piccinelli and Wilkinson, 2000). Treatment however, seems to be clearly articulated through the pharmacological and psychotherapeutic discourses of antidepressants and talking cures. This has important social and economic consequences. Of those people who presented at general practitioners with depression more than 50\% were women. In addition, 'Prescriptions for antidepressants in Australia tripled over the past decade from 12.4 defined daily doses (DDD)/1000 population per day (5.1 million prescriptions) in 1990 to 35.7 DDD's/1000 population per day (8.2 million prescriptions) in 1998' (McManus, Mant, Mitchell et al. in NSW Department for Women, 2001:7).

The emphasis on biomedical explanations and treatments means that the more complex social and cultural processes shaping women's experiences of depression, emotional wellbeing and mental illness remain poorly recognised. While public health research and policy does identify the risks of depression for women, the emphasis on population data means that gender has been conceptualised unproblematically as a 'variable' influencing mental health or illness. Despite the growing literature (Davis and Low, 1989; Russell, 1995; Karp, 1996; Healy, 1998; Stoppard, 2000; Kangas, 2001) there has been little sociocultural analysis within policy of how women's experiences and lay knowledge of depression are shaped by contemporary discourses about gender identity, emotional wellbeing and mental health risk. All health policy and promotion practices operate with implicit theories of risk behaviour (Beck, 1992; Bloor 1995; Gabe, 1995; Lupton 1999b). Unpacking and exploring the cultural construction of risk within mental health policy discourses enables us to critically examine how women are constituted as a population, and as individuals, at risk of depression. As Tait suggests, 'The flexibility of risk has meant that it has become an important component in a grid of governmental intelligibility; it also legitimates a broad range of governmental intervention' (2000:158). This kind of socio-cultural analysis involves exploring the implications of policy directions that define mental health risk and human emotions (such as sadness, dissatisfaction) in particular ways (for example, biomedical explanations).

In this article we draw upon the work of governmentality and risk theorists (Foucault, 1991; Rose, 1999; Dean, 1999; Lupton 1999) and feminist research into women's experience of depression (Stoppard, 2000) to develop an analysis of mental health policy that recognises the power-knowledge relations shaping how depression is conceptualised in terms of causality, risk, treatment and prevention. Governmentality theorists argue that policy discourses are a means through which neo-liberal rule is exercised in relation to particular 'risky' populations groups (Dean, 1999; Rose 1998). As Petersen (1997: 194) argues, 'Neoliberalism is a form of rule which involves creating a sphere of freedom for subjects so that they are able to exercise a regulated autonomy'. Policies, programs and health discourses within popular culture circulate constructions of individual risk that have been calculated through epidemiological studies of populations, such as women. Rather than presume women simply absorb 'dominant ideologies' about mental health risk and femininity, a governmentality approach emphasises how women are urged to take up and self manage certain constructions of risk as part of becoming a responsible neoliberal citizen. In this way power exercised through discursive domains like policy is understood to be 'productive' of the self, rather than simply repressive. The exercise of power within 
contemporary neoliberalism works through governmental imperatives (defining, treating and reducing depression) to mobilise our freedom to act and think about ourselves, our emotional responses to the world and hence our inner lives in historically specific ways. The practices through which women govern their emotional lives exist in a complex relation to the technologies of governance (professional advice, pharmaceutical marketing, media stories etc) that mobilise contemporary constructions of depression as an illness of mind and body. As we shall see later the experience of depression (and inner subjectivity) is not simply an ahistorical, universalised category of illness.

\section{Governing Depression}

Mental health policies have powerful 'truth' effects that shape contemporary understandings about depression and consequently the way it has been recognised (via clinical diagnosis DSM IV), subject to expert knowledge (via medicine or behavioural science) and dealt with (managed by health professionals and treated via the pharmaceutical industry). The whole apparatus of health care, which cannot simply be reduced to a singular notion of the State or homogenous understanding of the field of medicine, engages in the production and mobilisation of powerful discourses of expertise that work to problematise certain kinds of human experience as depression (Rose, 1998). This is not to suggest that such discourses are monolithic or uncontested within the domain of mental health or within the wider realm of popular culture, nor dispute that current treatment protocols have some success. The issue resides within a broader concern that depression is generally not explored (given the dominance of randomised control trials) in relation to women's emotional experiences of unhappiness, sadness, existential dilemmas, conflicts of identity, boredom and dissatisfaction with gender expectations and the increasingly time-governed order of work-leisure-home-community life.

In contrast to the Commonwealth level we have seen State developments in mental health policy and promotion that do recognise the socio-cultural nature of wellbeing and the impact of inequitable power relations (see VicHealth for example, Moodie and Verins, 2002), which incorporates gender but not explicitly. In New South Wales recent policy changes in women's health have identified the need for a gendered approach to depression that makes explicit the socio-cultural context of mental health and illness (NSW Health, 2002). Australian policy also exists with a network of global relations of governance with respect to the imperatives of the World Health Organization and trends within America, Canada and England. From this perspective we can see how the discursive field of mental health policy in Australia is a site of multiple interpretations and truths about how depression should be governed.

When we examine significant policy driven initiatives, such as the national beyondblue website, we see a convergence of particular biomedical discourses into a contemporary 'evidence base' that constructs a particular truth about depression and its treatment for women (see Ellis and Smith, 2002). By logging onto the beyondblue bulletin board (for example the 'Experiences with Postnatal Depression, posted 5/3/2002, www.beyondblue.org.au/site/bulletin/show.a sp?topic id $=372$ accessed 22/7/2002) we can see how women are struggling to understand and manage their experiences of depression in relation to childcare, poverty, workplace issues, sexual demands from partners etc. With the 'expert' advice of psychiatrists these women are consistently guided to think about their emotional distress in pharmacological and 
psychotherapeutic terms. Rarely is there any reference to the social, cultural and political dimension of women's lives that may indeed contribute to their feeling of being overwhelmed, undervalued, pressured and unable to manage autonomously. Many women experiencing depression and using this bulletin board clearly identify a host of problems with their antidepressant treatment (lack of libido, withdrawal, fear of dependency etc) and professional support (cost, waiting lists and rigid assessment criteria). Yet women's responsibility for the problem is continually reiterated by experts who reinforce dominant practices. Where, in this regime of truth, is there room for women to ask critical questions about their own experiences of emotions and selfhood in contemporary culture and importantly to be heard?

Curiously the cultural and historical processes that are so significant in shaping the mental health of Aboriginal and Torres Straight Islanders have been recognised in the National Action Plan for Depression (CDHAC, 2000a). Yet, gender remains largely invisible in relation to either the cultural identity of population groups or the individual's mental health experiences. By ignoring the gendered nature of depression policy strategies may actually work to perpetuate dominant understandings about women's wellbeing that may in fact limit ways of thinking about alternatives, solutions and the socio-cultural determinants that shape women's experiences of depression in contemporary neo-liberal society.

We argue that what contemporary mental health policy discourses (whether behavioural or biomedical) collectively produce are dominant understandings of depression that individualise women's emotional experiences by ignoring gender relations. In this sense policy discourses work to govern the emotional wellbeing of women 'at a distance' via strategic directions that mobilise particular mental health professionals and agencies to think and respond to women in certain ways. An example of how depression is often individualised at the expense of more complex understandings exists in relation to how depression in older women living in residential care is attributable to their poor physical health, rather than the institutional setting (see CDHACa, 2000:6). This explanation ignores the effects of institutional power relations that regulate the lives of older women in ways that foster dependency upon health professionals and may contribute to a sense of powerlessness, invisibility, meaninglessness and hence depression. If there is no critical analysis of socio-cultural processes and power relations then it is unlikely that they will figure in any solution focused intervention. We can see how older women become constituted as an at risk population that requires specific highly medicalised interventions and thus depression is understood by health professionals, families and women themselves as an individual problem requiring pharmacological intervention, thus mollifying dissent (see for example the power relations at work in psychiatric nursing, Morrall and Muir-Cochrane, 2002). This is not to say that counter discourses about depression do not exist to challenge these established truths, however, the resistance of older women may well be reinterpreted again as part of the 'mental health problem' (they are simply 'noncompliant').

\section{Governing the Self}

Governmentality theorists argue that modern individuals are increasingly urged to consider their everyday lives and wellbeing in terms of a lifelong project of self improvement and lifestyle optimisation (Rose 1990, 1996, 1999). We can see this imperative embodied in the World Health 
Organization (WHO) definition of mental health that underpins Australian policies aimed at reducing depression and promoting mental wellbeing. It is defined as:

A state of emotional and social wellbeing in which the individual realises his or her own abilities, can cope with the normal stresses of life, can work productively or fruitfully, and is able to make a contribution to his or her community (CDHAC, 2000c:3).

Defining health as more than the absence of disease is far 'more problematic for mental than physical health' (Sainsbury, 1998:46). The WHO definition suggests that mental health is elusive, something constantly strived for and dependent upon individual abilities or realised potential. Hence, mental health policies work to govern at a distance emotional wellbeing by urging individuals to engage in certain modes of relating to the self through practices of self examination, self care and self improvement (Petersen, 1997). We can see how the popular discourses of mental health are mobilised through psychological notions of selfesteem, self-worth and self-image. Such discourses permeate popular culture and work, in largely unintended ways, to shape the way women come to think about and act towards themselves (their subjectivity) and their emotions in times of distress, deep unhappiness, dissatisfaction and sadness (Lupton, 1999b). We are urged to constantly monitor our mental health risk, our stress levels, our coping mechanisms and our intimate relationships. Women are also subject to the cultural imperative that requires them to be responsible for the wellbeing of ageing parents, children and partners often at the expense of their own emotional life (Stoppard, 2000).

Expert knowledges about mental health risks in policy and professional domains that draw upon psychological discourses tend to presume a rational model of choice and behaviour at the individual and population levels. Risk is rendered manageable and measurable through epidemiological discourses that identify depression as a population health problem (Lupton, 1999b). Emphasis is placed upon prevention and changing environments that contribute to depression as well as early intervention at the individual level for those at risk. Yet, constituting particular groups of people, such as women, as 'at risk' of mental health problems also serves to position individuals as vulnerable, weak, powerless and in need of professional expertise and advice on how to live, how to manage emotions, and subject the mind and body to a variety of treatments if self-management fails (Lupton, 1999b).

\section{Mental Health Literacy: Risk Reduction Strategies}

The epidemiological calculation of risk provides the rationale for policy initiatives that govern women's mental health through strategies that aim to improve mental health literacy as a means of increasing lay knowledge about the symptomatology and pathways of treatment for depression. However, there are problems with promoting mental health literacy without acknowledging the gendered nature of depression. Australian researchers examining the mental health literacy of the general population identified a gap between public perceptions about depression and its treatment, and the 'expert' knowledge of mental health professionals (Jorm, Korten, Jacomb et al.,1997). Public perceptions about the value of treatments for depression placed greater emphasis on alternative, nonmedical interventions (relaxation, vitamins, exercise etc), than conventional medical, pharmacological and psychological therapies. The researchers concluded that the population demonstrated low levels of mental health literacy through a lack of concurrence with professional expertise (Jorm, Korten and Jacomb, 1997). This 
finding ignores the kinds of cultural discourses that inform lay perceptions about depression and its management (social, biomedical and lifestyle related). The study assumes that men and women are merely ignorant about current expert definitions of symptomatology and treatment for depression. In other words they do not know the 'truth' about depression and how to manage themselves in relation to calculated mental health risk. What we need to understand further is how public perceptions are shaped by popular discourses and gendered expectations that produce an identification with professional expertise, or a refusal and adoption of other sources of knowledge (Lupton, 1999b).

While gender differences in the experience of depression and its management are well known there has been little research into the gendered nature of mental health literacy in relation to different sources of health information such as magazines, the Internet, social networks, television, health professionals and policies. A gendered approach would consider how women construct meaning about depression and emotional distress from conversations with friends and family, the popular media, policy directions and professional expertise. A gendered analysis would also consider how women perceive help seeking options and how they explain depression in relation to norms about feminine identity and roles within the specific contexts of their communities (Stoppard, 2000).

Recent Canadian research by Scattolon and Stoppard (1999) investigated rural women's experiences of depression and coping. It identified the complex social relations that governed how women defined their emotional distress. The majority of women felt very uncomfortable about identifying themselves as depressed and very few adopted medicalised explanations for depression or sought professional help. They tended to 'normalise' their experiences in the context of life stress arising from poverty, rural isolation and a lack of support for gendered roles such as mothering. These women do not necessarily have low levels of mental health literacy. Rather, they interpret depression in relation to the socio-cultural context of a rural community where the stigma attached to mental illness is pervasive and where women are governed by entrenched norms about feminine identity that provides them with little support. By asking different questions and utilising a range of qualitative methods a gendered analysis could compliment existing approaches to mental health literacy by opening up alternative ways of investigating the relationships between women's everyday knowledge about depression and the sociocultural context that shapes it. However, we also need to consider the broader historical context in which our present-day understandings of women's depression exist.

\section{Depression: A History of the Present}

Knowledge produced about depression through health policy discourses is also mediated through particular historical relations with medicine (particularly psychiatry) and the pharmaceutical industry. Depression as we know it today is a particularly modern phenomenon - a diagnosis of depression did not exist prior to 1900 (Healy, 1997). Apart from the more floridly psychotic forms of depressive illness, which would have been termed madness, what we now call depression would have been seen as melancholia or sadness. Stearns (1993: 553), reviewing anthropological and historical documents, points out that the distinction between sadness and depression reflects cultural preparedness or unwillingness 'to offer succour'. In many cultures there is, Stearns (1993: 555) observes, 'an association 
between sadness and passivity, and a fear of the latter as dangerous.' It is a fear which, in modern societies, leads to a minimising of sadness and places increased pressure on the sad person to quickly solve his or her problems. Feminists have identified the way in which emotion and mental distress has been associated with the feminine realm of humanness, the body and home, which has been defined historically in opposition to the masculine sphere of reason, intellect and public life (Russell, 1995).

The modern day imperative to rationally manage the emotions that render the self passive is produced through a patriarchal and neo-liberal demand that individuals become experts at self-governance. By assuming an implicitly masculine model of humanness as the norm we are all urged to become our own motivators, health promoters and illness managers in conjunction with dominant forms of expertise derived from the psy-professions (Lupton, 1998; Rose 1999). In this way certain emotional experiences have become constituted as mental health disorders with accepted diagnostic categories and treatment modalities that rely upon new distinctions between normal and abnormal, and old distinctions between femininity and masculinity. While depression research identifies the problem to be higher amongst women the complex relationship between feminine norms that facilitate the recognition of the emotional self, and the medicalised diagnosis of human experience (based upon implicitly masculine norms) as illness, remains unacknowledged.

Over the years there has been a marked increase in diagnostic categories in the Diagnostic and Statistical Manual for Mental Disorders, from 180 in DSM II to 350 in DSM IV (Healy, 1997). Depression is currently defined according to the following categories (a) bipolar mood disorder (formerly manic-depression), (b) psychotic depression, (c) depressive episode, (d) postnatal depression and (e) adjustment disorder with depressed mood. The first four are assumed to have biological causes, such as changes in brain biochemistry or hormonal fluctuations. The response to lithium carbonate in the case of bipolar disorder, to antidepressants in depressive episodes, and to ECT and antipsychotics in the more severe experiences of depression appears to justify the proposition that some depression may be associated with physiological changes. However, the status of category (e) diagnosis is less certain. This disorder is described as a psychosocial reaction to distressing situations in life (eg, job loss) but to a greater degree than usual (CDHAC, 2000a).

In the absence of any absolute diagnostic test for depression such as is usually the case with physical diseases, the assignment of a DSM diagnosis of 'depressive disorder' is problematic in Stoppard's (2000) view as it calls for a clinical interpretation of symptoms. Depressive symptoms are interpreted in terms of behaviour change that indicates a 'marked change from previous functioning' or 'increasing irritability' and so on. Stoppard (2000) argues that the degree to which such behaviour changes occur is arbitrarily defined; indeed how much change in emotional and behavioural states is necessary for a diagnosis of depression? These dilemmas of definition in relation to depression are significant in relation to the way policy works to govern an increasing number of women experiencing some form of emotional distress. Two dilemmas are posed by the National Action Plan for Depression (CDHAC, 2000a: ix, 19): what might be the best strategy for treating milder but disabling symptoms of depression and how best can depressive symptoms be assessed when they do not meet internationally recognised criteria for depressive disorders. Both of these issues suggest a widening of the 
boundaries of how depression is identified and hence an extension of governance over women's emotional lives through medical and psychological intervention.

The National Action Plan for Depression clearly relies upon psychological and biomedical discourses to constitute depression in terms of individual vulnerability to adverse life events that can also indicate a genetic predisposition. It states that, "vulnerability may be the result of the person's thinking style, tendency to worry or to be impulsive, poor social skills, poor social support and poor problem solving skills' (CDHAC, 2000a: 3). This psychologisation of depression is accompanied by evidence suggesting a genetic explanation of vulnerability as inherited. Apart from the reference to ATSI mental health there is no acknowledgment of social factors (such as gender) and cultural processes (such as sexism, racism, homophobia, ageism and other forms of discrimination) that might contribute to an individual's experience of adverse life events. In fact, the National Action Plan for Depression (CDHAC, 2000a) does not even incorporate insights from the previous National Health Priorities Areas Report on Mental Health (CDHAC, 1998:2), which focused on depression, and clearly stated how general social-emotional ill health can result from oppression, racism and economic factors. Within the national mental health policy framework for addressing depression we are left with two alternatives when trying to understand women's experiences; (a) depression is biological and genetic (though this does not explain why there is an 'epidemic' of depression) or (b) depression is a personality weakness where women lack the coping skills to be resilient in the face of life difficulties.

Stoppard's (2000) key analysis of gender and depression points to the importance of researching women's own experiences as a valid source of knowledge. She says,

... a focus on women's accounts allows the discursive conditions shaping women's experiences within specific sociocultural contexts to be explored. Included here would be discourses about depression, the meaning of depressive experiences, and their causes and implications for women's lives. Such discourses represent resources drawn on by women in their attempts to understand and make sense of their depressive experiences (Stoppard, 2000:38).

More needs to be known about how depressive experiences are interpreted, what actions women take as a consequence of those interpretations, and the results of those actions. Sociocultural research into the gendered discourses that shape the experience of depression could inform policy and practice in new ways (Stoppard, 2000). Healy (1997:109) points out that there is a lack of evidence concerning 'the appropriate management of milder depressions and perhaps even fundamental misunderstandings about the nature of such depressions'. A diagnosis of depression often leads to drug therapy, perhaps for life or in repeated cycles of medication provoked by fear of relapse, a fear triggered by feelings of apparently irrational sadness. Non-drug therapies are suggested (psychotherapy) for adjustment disorder with depressed mood. However, the financial constraints that many women experience because of their social position and the high cost of psychological therapies means that medical expertise (the bulk billing general practitioner) becomes the dominant pathway for dealing with emotional issues. Women as 'good healthy citizens' are expected to assume responsibility for their health and consult medical expertise in the process of reducing the risk of disease and optimising health (Petersen and Lupton, 1997). 
Rose argues that doctors and psychotherapists are positioned as the 'experts of subjectivity' who transfigure existential questions about the meaningfulness of one's life and sociopolitical questions about happiness (e.g. should I stay married, have children and leave work, try to look younger, slimmer etc), into technical questions about the most effective ways of coping or managing one's emotional life and malfunction (Rose 1996:154). Treatments for depression determined by medical expertise are also implicated in the aggressive promotion of antidepressant drugs by pharmaceutical companies, which in turn normalises the medicalised management of emotion within contemporary society. As drug therapies become the dominant means of 'treating' women's depression we are witnessing the silencing of any cultural or feminist critique that would examine alternative understandings of women's emotional wellbeing and investigate the sociocultural forces that shape depression as a gendered phenomenon. The proliferation of medical and psychological categories of abnormality circulate new norms that shape how emotional life is understood within the broader apparatus of health care and popular culture. As Stoppard (2000) points out expert knowledges are circulated through the everyday domains of culture (e.g. television infotainment, magazines, etc) in ways that regulate how women think about and manage themselves in relation to norms of health and illness. These dominant discourses largely ignore the gendered nature of social life and hence the inequities women face that can contribute to depression.

\section{Concluding Remarks}

To conclude, we argue that the contemporary experience of depression cannot be separated from the cultural knowledges that now proliferate about it. We echo Petersen's (1997) call for a broader range of research and analytic approaches to investigate the effects of public health policies on contemporary experiences of self. He says, 'there has been relatively little exploration of the processes of selfsubjection associated with the multiple imperatives of public health' (Petersen 1997:203). There is also an urgent need to counter the gender blindness of mental health policy that serves to make invisible women's experiences. Policies that ignore the social and political forces shaping the cultural nature of our intimate relations with our selves and each other, are limited and limiting, as a basis for addressing issues like depression as they affect our emotional wellbeing. 


\section{References}

Beck, U. (1992) Risk society: Towards a new modernity. London, Sage.

Beyondblue Bulletin Board: Experiences with Postnatal Depression page, posted 5/3/2002, Available: www.beyondblue.org.au/site/bulletin/show.asp?topic id=372 (accessed online 22 July 2002).

Bloor, M (1995) The Sociology of HIV Transmission. London, Sage.

Australian Institute for Health and Welfare. (2000) Australia's Health 2000. Cat. No.19, Canberra, AIHW.

Commonwealth Department of Health and Aged Care. (1999) National Health Priority Areas Report: Mental health, a report focusing on depression (Summary 1998). Cat. No. PHE 14, Canberra, AIHW \& CDHAC.

Commonwealth Department of Health and Aged Care. (2000a) National Action Plan for Depression 1998-2003. Canberra, Mental Health and Special Programs Branch, CDHAC.

Commonwealth Department of Health and Aged Care. (2000b) National Action Plan for Promotion, Prevention and Early Intervention for Mental Health 2000. Canberra, Mental Health and Special Programs Branch, CDHAC.

Commonwealth Department of Health and Aged Care. (2000c) Promotion, Prevention and Early Intervention for Mental Health: A Monograph. Canberra, Mental Health and Special Programs Branch, CDHAC.

Davis, D. \& Low, S. (1989) Gender, Health and Illness: The case of nerves. New York, Hemisphere Publishing.

Dean, M. (1999) Governmentality: Power and rule in modern society. London, Sage.

Ellis, P. \& Smith, D. (2002) Treating Depression: The beyondblue guidelines for treating depression in primary care. Medical Journal of Australia, 176, (10 supplementary), ppS77-83. http://www.mja.com.au/public/issues/176_10_200502/ell10082_fm.html

Foucault, M. (1991) Governmentality. In Burchell, G. et al. (Eds.), The Foucault Effect London, Harvester Wheatsheaf. pp. 87-104

Gabe, J. (1995) Health, Medicine and Risk: The need for a sociological approach. In Gabe, J. (Ed), Medicine, Health and Risk: Sociological Approaches, Oxford, Blackwell. pp 1-17

Healy, D. (1998) The Anti-Depressant Era. Cambridge, Harvard University Press. 
Jorm, A., Korten, A., Jacomb, P., et al, (1997) Mental Health Literacy: A survey of the public's ability to recognise mental disorders and their beliefs about the effectiveness of treatment. Medical Journal of Australia 166, pp182-186.

Kangas, I. (2001) Making Sense of Depression: Perceptions of melancholia in lay narratives. Health 5(1), pp76-92.

Karp, D. (1996) Speaking of Sadness: Depression, disconnection and the meanings of illness. Oxford, Oxford University Press.

Lupton, D. (1998) The Emotional Self. London, Sage.

Lupton, D. (1999a) Risk and Sociocultural Theory. Cambridge, Cambridge University Press.

Lupton, D. (1999b) Risk. London, Routledge.

McManus, P. Mant, A., Mitchell, P., et al. (2000) Recent trends in the use of antidepressant drugs in Australia, 1990-1998, Medical Journal of Australia, 173, pp458-461.

Moodie, R. \& Verins, I. (2002) Guest Editorial: To whom does mental health belong? Australian e-Journal for the Advancement of Mental Health, 1 (2), http://www.auseinet.com/journal/voll iss2/moodie.pdf

Morrall, P. \& Muir-Cochrane, E. (2002) Naked Social Control: Seclusion and psychiatric nursing in post-liberal society. Australian e-Journal for the Advancement of Mental Health, 1 (2), http://www.auseinet.com/journal/voll iss2/morrall.pdf

Murray, C. \& Lopez, A. (1996). The Global Burden of Disease: A comprehensive assessment of mortality and disability, injuries, and risk factors in 1990 and projected to 2020. Geneva: World Bank, Harvard School of Public Health and World Health Organization.

NSW Health Department. (2002) Women's Health Outcomes Framework. Sydney, NSW Health.

NSW Department for Women. (2001) Young Women's Health: Depression and risk taking behaviour. Sydney: NSW Department for Women.

http://www.women.nsw.gov.au/pdf/young_womens_health.pdf

Petersen, A. (1997) Risk, governance and the new public health. In Petersen, A. \& Bunton, R. (Eds.) Foucault, Health and Medicine. London, Routledge. pp 189-206

Petersen, A. \& Lupton, D. (1997) The New Public Health. London, Sage.

Piccinelli, M \& Wilkinson, G. (2000) Gender Differences in Depression: A critical review. British Journal of Psychiatry. 177, pp486-492.

Rose, N. (1998) Governing Risky Individuals: The role of psychiatry in new regimes of control. Psychiatry, Psychology and Law 5, pp177-195. 
Rose, N. (1990) Governing the Soul: The shaping of the private self. London, Routledge.

Rose, N. (1996) Inventing Ourselves: Psychology, power and personhood. Cambridge, Cambridge University Press.

Rose, N. (1999) The Powers of Freedom: Reframing political thought. Cambridge, Cambridge University Press.

Russell, D. (1995) Women, Madness and Medicine. Cambridge, Polity Press.

Sainsbury, P. (1998) Comment: Promoting mental health in NSW. NSW Public Health Bulletin. 9 (4), pp46-50.

Scattolon, Y. \& Stoppard, J. (1999) 'Getting on with life': Women's experiences and ways of coping with depression. Canadian Psychology. 40(2), pp205-219.

Stearns, C. (1993) Sadness. In Lewis, M \& Haviland, J. (Eds.), Handbook of Emotions.

New York, Guilford Press. pp547-562

Stoppard, J. (2000) Understanding Depression: Feminist social constructionist approaches. London, Routledge.

Tait, G. (2000) Youth, Sex and Government. New York, Peter Lang.

Thornicroft, G. \& Betts, V. (2002) International Mid-Term Review of the Second National Mental Health Plan for Australia. Canberra, Mental Health and Special Programs Branch, Department of Health and Ageing. 